\title{
Universal Models and Platforms in E-Learning
}

\author{
https://doi.org/10.3991/ijet.v16i09.19697 \\ Viktor Shurygin $\left({ }^{(x)}\right.$ \\ Elabuga Institute of Kazan Federal University, Elabuga, Russia \\ viktor.shurygin085@gmail.com \\ Anna Berestova, Tatiana Litvinova \\ I. M. Sechenov First Moscow State Medical University, Moscow, Russia \\ Eugeny Kolpak \\ Saint Petersburg State University, Saint Petersburg, Russia \\ Alesya Nureyeva \\ Elabuga Institute of Kazan Federal University, Elabuga, Russia
}

\begin{abstract}
The study describes the effectiveness of digital technological solutions in education. Students, postgraduates, teachers, and medical business representatives have tested a comprehensive educational product based on the capabilities of learning management system (LMS) platforms. The online course was implemented on the e-learning platforms such as Moodle, Schoology, TalentLMS, Canvas LMS, Docebo, iSpringLearn's, Brightspace, Absorb LMS. The implementation of advanced e-learning models ensured the effectiveness of the educational process. The focus on the development of the personal potential of each educational process participant made it possible to create a personalized learning environment and evoke a sense of personal significance and importance. The focus on feedback has created a creative communication environment for the exchange of knowledge, thoughts and ideas satisfying participants' educational needs for self-expression and creativity. The collective creativity of the educational process participants made it possible to develop a high-quality corporate culture of the students involved, which became the basis for establishing business partnerships in the system of education, science, and business. Based on the observations, a universal model of an effective educational process in the digital age has been developed.
\end{abstract}

Keywords-E-learning, online platforms, learning management systems (LMS), advanced learning technology

\section{Introduction}

The conceptualization of the use of computerized systems to ensure or facilitate the educational process is based on the use of technological solutions for educational purposes (for example, online learning, virtual learning, distance learning, mobile learning, MOOC, learning management systems) [1]. The digital transformation of 
the education systems has introduced a new ecosystem of teaching and learning - elearning.

The concept of e-learning is a technology-mediated learning approach that has great educational potential [2]; it is an innovative web-based system developed based on digital technologies and other forms of instructional material which primarily aims to provide learners with a personalized, student-centered, open, enjoyable and interactive learning environment that supports and enhances learning [3]. There are four general definitions of e-learning, namely: (1) technology-driven learning relying on the use of technology to deliver education and training programs; (2) the delivery of education, training, or educational programs by electronic means; (3) learning focused on communication and facilitated by the use of digital tools and content that involves some interaction between the student and the teacher or peers; and (4) learning focused on the educational paradigm, that is information and communication technologies used to encourage students improve their learning experience [4]. E-learning should not be confused with the concept of blended learning, which is defined as the effective integration, or fusion, of face-to-face and online learning in accordance with the educational needs and goals of students [5].

A number of web resources integrated into virtual learning platforms allow the selection and adaptation of information, collaboration and learning resources [6]. Higher education students have a variety of ICT resources offering integrated media typologies such as RICA (information, collaboration, and learning) [7] or SECTIONS (students, ease of use, costs, teaching functions, interaction, organization, networking, security) [8].

One of the segments that has gained popularity with the advancement of digital technologies is the Massive Open Online Courses (MOOCs). The growing popularity of MOOCs in higher education is rather noticeable. Today the possibility of integrating MOOCs into traditional education is being considered in many countries. Innovators in higher education see great potential in MOOCs. The peculiarity of MOOCs is that they offer a method of learning aimed at a large group of students and based on mutually learning. Educational online courses are offered by prestigious universities in partnership with MOOC providers such as Coursera, Udx, Udemy, Udacity, etc. MOOCs require minimal costs and open up great educational opportunities making learning accessible regardless of location or financial status of students [9].

Online learning platforms are important in modern education; they provide educational process participants with the following advantages: free access, lower tuition fees, the possibility of breaking the e-course into modules, flexibility of learning, clear criteria for assessing knowledge [10]. The use of learning platforms responds to the challenges of distance learning in higher education by customizing tasks and adapting the presentation of content to virtual support combined with traditional materials [11]. Online learning platform in higher education should be adapted to the knowledge and practices of the virtual environment (e-learning and b-learning) encouraging assimilation of knowledge and autonomous learning, as well as effective interaction with teachers in the course of completing educational tasks [6].

As online courses are gaining popularity, teaching strategies must be carefully designed to provide learners with a quality learning experience and compensate for the 
distance associated with space and time. These strategies should contribute to the student to teacher, student to student, and student to content interaction. To ensure the effectiveness of distance education, a comfortable learning environment based on trust and communication, as well as a sense of social presence that allows students to feel connected with their teachers, peers and the online class, should be created [12].

In view of this, the purpose of the study is the search for the best solutions, models, and platforms to ensure the success of e-learning, which would satisfy the increased demand for innovative educational support for the professional activities of medical enterprises, expand the scope of business contacts and contribute to the establishment of business relationships within the system of education, science, and business. To achieve this goal, the following tasks have been set:

- To develop an innovative comprehensive educational product - Management of corporate culture of a company in the digital dimension - which would generate synergies between advanced distance learning models making a qualitative breakthrough in modern educational trends;

- To develop an effective study group involving the representatives of education, science and medical business;

- To test the online course with the help of the digital learning platforms selected in accordance with the following criteria: mobile accessibility; scalability; ease of use and customization; content creation and content management;

- To review the models and platforms of distance learning included in the course;

- To analyze the educational practice from the perspective of the course developers and identify effective pedagogical approaches and methods in the e-learning environment;

- Based on the observations to develop a universal model of an effective educational process in the digital age.

\section{$2 \quad$ Materials and Methods}

Learning Management Systems (LMS) are widely used in global education systems [13]; they are designed to develop, manage and deliver educational content online by providing students and educators with a platform to teach and demonstrate their skills anywhere and anytime. A Learning Management System is an application for the development of curricula and courses, administration and tracking of the process of individual development, drawing up reports on the effectiveness and efficiency of educational practices, thereby providing technology-enhanced learning. Students are given access to the educational content and services provided by the course developer from the learner portal that an LMS always has.

Technology-enhanced learning (TEL) releases teachers from complex administrative and bureaucratic responsibilities by helping them automate routine paperwork. This is possible through the use of artificial intelligence methods, which allows teachers to focus on their core responsibilities, namely teaching, research and mentoring students [14]. Research conducted over the past 30 years has shown that effective and tailored approaches can be achieved through artificial intelligence and intelligent 
learning environments (ILE). ILEs are technology-enhanced learning systems designed to provide adaptive and interactive learning. These systems include tactical training systems and intelligent training systems such as the ASSISTment platform [15].

Vendors usually provide LMSs that are targeted at educational and corporate environments. Today, there is a large range of learning management software that is used by educational institutions and businesses.

LMS in an educational institution is a tool that ensures a centralized and consolidated repository of educational data. Educational content is provided on a common platform that students can access anywhere and anytime. LMS capabilities allow catering to the individual needs of each student and providing a unique learning experience by creating a learning path using different courses. LMS promotes group interaction, exchange of views, collaboration on various projects or assignments, thereby forming an interest in learning and a high level of student involvement.

In the business segment, LMS contributes to an increase in labor productivity through effective training of employees and the development of their labor potential. LMS can also be a tool for recording, maintaining and assessing employee performance. LMS helps businesses retain employees by offering them career opportunities based on the acquisition of additional skills [16].

Both educational institutions and corporations use Learning Content Management Systems (LCMS), which are focused on digital learning as the basic educational model and are designed to create e-learning content. On the other hand, LMS platforms are not exclusively focused on digital learning but they also support face-to-face and blended learning. Functionally, there are a number of overlaps and key differences between LMS platforms and learning content management systems. The main function of e-learning software is to provide the user with a large library of content for self-study or the integration with the LMS platform. However, LMS platforms may not offer content libraries at all. Instead, they focus on the learning process management, as well as storing and tracking individual / cumulative progress. Most vendors offer e-learning software that can be integrated with the LMS platform [17].

The terms "virtual learning environment" (VLE) and "learning management system" are often used synonymously. However, being the same products, they emphasize different aspects of the software. Virtual classrooms are focused on the collaborative aspect of learning having the dominant functions of discussion, forum or student collaboration. LMS has traditionally been referred to as a product with strong tracking and performance analysis capabilities. Most LMS vendors have strengthened the virtual classroom aspects of their platforms as virtual learning has become either more financially or socially attractive [17].

In addition, in modern educational practices, there are four generations of elearning pedagogy: behaviorist / cognitivist, social constructivist, connectivist, and holistic pedagogy. The relevance of each pedagogical approach depends on the technological capabilities used in pedagogical activities. The holistic generation includes learning analytics, collaborative technologies, deep learning and artificial intelligence, disaggregated tools and services, mobility and device diversity, IoT and ubiquitous computing, virtual and augmented reality and 3D printing. Next-generation pedagogy is characterized by a) the focus on a student; (b) technical, social and organizational distribution; (c) massive support and emergence; (d) integration, timeliness, and au- 
thenticity; (e) reduced importance of courses; and (f) separation of training from accreditation [18].

\subsection{Research design}

Teachers of three higher educational institutions of the Russian Federation (Yelabuga Institute of KFU, Institute of Leadership and Healthcare Management of I.M.Sechenov First Moscow State Medical University, Higher School of Management of St. Petersburg State University) developed a comprehensive distance learning course - Management of corporate culture of a company in the digital dimension intended for companies operating in the medical business. The teachers (curators of the course) were asked to design an integrated and relevant educational product in the medical business with the maximum use of digital tools and learning management systems, the implementation of which would ensure interaction between education, science and business, facilitate the exchange of knowledge and become a platform for generating innovative solutions. The duration of the educational program was 4 months; it was tested from February 2020 to June 2020.

The course features are as follows:

- The course consisted of 8 modules and was guided by 8 curators;

- The course was developed based on a marathon pattern; thus, each module was designed and implemented by one teacher, which thematically diversified the educational product;

- A separate Learning Management System (LMS) was used in each module; thus, allowed participants to gain a variable digital educational experience;

- A group of students consisted of postgraduate students and teachers (37 people), students (40 people), executives, managers and personnel of medical business companies (130 people), which made it possible to shape a professional interest in gaining knowledge and make the participants realize the strategic importance of the acquired experience of group interactions;

- A problem-based approach with the elements of gamification defined the conceptual integrity of collective interaction in the course development;

- Mobile learning tools ensured the maximum level of involvement and attention of students reducing distraction and maintaining the strongest online presence;

- The implementation of advanced e-learning models ensured the effectiveness of the educational process;

- The focus on the development of the personal potential of each educational process participant made it possible to create a personalized learning environment and evoke a sense of personal significance and importance;

- The focus on feedback created a creative communication environment for the exchange of knowledge, thoughts and ideas satisfying participants' educational needs for self-expression and creativity;

- The collective creativity of the educational process participants made it possible to form a high-quality corporate culture of the students involved, which became the basis for establishing business partnerships in the system of education, science and business. 


\subsection{Research limitations}

The course "Management of corporate culture of a company in the digital dimension" was tested outside the format of educational courses and training programs of higher educational institutions. The group was diversified in order to imitate the pedagogical style of social learning, which is a perfect tool for the formation of synergistic interaction, partnership, and business cooperation; this, in turn, made it possible to realize the purpose of the course.

\subsection{Review of the distance learning platforms included in the course}

The online course was implemented on the e-learning platforms such as Moodle, Schoology, TalentLMS, Canvas LMS, Docebo, iSpringLearn's, Brightspace, Absorb LMS.

The selection was based on the following criteria:

1. Mobile accessibility. Due to the growing popularity and rapid development of mobile learning among a wide audience of students, the focus of the learning management system on mobile devices is an important factor in determining the functional value of the platform in the implementation of educational goals.

2. Scalability. The scope of available features, pricing models, cloud and on-premises frameworks help maximize the potential of educational programs. It is crucial to create a clear, measurable and achievable goal to be realized through e-learning.

3. Ease of use and customization. The LMS platform should be as clear and userfriendly as possible - a tool for issuing and accepting educational value.

4. Content creation and content management. Available LMS platforms vary in their focus on content and administration capabilities. The dynamics of technology make it important to define the priority function in the integration of LMS. 
Table 1. LMS platforms

\begin{tabular}{|c|c|c|c|c|c|c|c|c|c|c|c|c|c|}
\hline \multirow[b]{2}{*}{ LMS } & \multirow[b]{2}{*}{ Deployment } & \multicolumn{12}{|c|}{ Technological capabilities } \\
\hline & & $\begin{array}{l}\text { aca- } \\
\text { demic } \\
\text { edu- } \\
\text { cati- } \\
\text { on }\end{array}$ & $\begin{array}{l}\text { cor- } \\
\text { po- } \\
\text { rate } \\
\text { and } \\
\text { busi- } \\
\text { ness } \\
\text { edu- } \\
\text { cati- } \\
\text { on }\end{array}$ & $\begin{array}{c}\text { blend } \\
\text { ed } \\
\text { learn- } \\
\text { ing }\end{array}$ & $\begin{array}{l}\text { asyn- } \\
\text { chro- } \\
\text { nous } \\
\text { learn- } \\
\text { ing }\end{array}$ & $\begin{array}{l}\text { syn- } \\
\text { chro- } \\
\text { nous } \\
\text { learn- } \\
\text { ing }\end{array}$ & $\begin{array}{c}\text { stu- } \\
\text { dent } \\
\text { portal }\end{array}$ & $\begin{array}{c}\text { mo- } \\
\text { bile } \\
\text { learn- } \\
\text { ing }\end{array}$ & $\begin{array}{c}S C O \\
\text { RM } \\
\text { com- } \\
\text { pli- } \\
\text { ance }\end{array}$ & $\begin{array}{l}\text { video } \\
\text { con- } \\
\text { fer- } \\
\text { ences }\end{array}$ & $\begin{array}{c}\text { in- } \\
\text { built } \\
\text { cours } \\
e \\
\text { de- } \\
\text { velop } \\
\text { ment }\end{array}$ & $\begin{array}{c}\text { gami- } \\
\text { fica- } \\
\text { tion }\end{array}$ & $\begin{array}{c}E- \\
\text { com- } \\
\text { merce }\end{array}$ \\
\hline Moodle & \begin{tabular}{|l|} 
Installed - \\
Mac, In- \\
stalled - \\
Windows, \\
Web-Based, \\
Cloud, \\
SaaS, iPh- \\
one / iPad \\
Android
\end{tabular} & + & + & + & + & + & + & + & + & + & + & + & - \\
\hline Schoology & $\begin{array}{l}\text { SaaS/Web/C } \\
\text { loud, Mobile } \\
\text { - Android, } \\
\text { Mobile - } \\
\text { iOS }\end{array}$ & + & + & + & + & + & + & + & + & + & + & + & - \\
\hline TalentLMS & $\begin{array}{l}\text { Web-Based, } \\
\text { Cloud, } \\
\text { SaaS, iPh- } \\
\text { one / iPad, } \\
\text { Android }\end{array}$ & + & + & + & + & + & + & + & + & + & + & + & + \\
\hline $\begin{array}{l}\text { Canvas } \\
\text { LMS }\end{array}$ & $\begin{array}{l}\text { SaaS/Web/C } \\
\text { loud }\end{array}$ & + & + & + & + & + & + & + & + & + & + & + & - \\
\hline Docebo & $\begin{array}{l}\text { Web-Based, } \\
\text { Cloud, } \\
\text { SaaS, iPh- } \\
\text { one / iPad } \\
\text { Android }\end{array}$ & + & + & + & + & - & + & + & + & + & - & + & + \\
\hline $\begin{array}{l}\text { iSpring- } \\
\text { Learn's }\end{array}$ & $\begin{array}{l}\text { Web-Based, } \\
\text { Cloud, } \\
\text { SaaS, iPh- } \\
\text { one / iPad } \\
\text { Android }\end{array}$ & + & + & + & + & + & + & + & + & + & + & + & - \\
\hline Brightspace & $\begin{array}{l}\text { Web-Based, } \\
\text { Cloud, SaaS }\end{array}$ & + & + & + & + & + & + & + & + & + & + & + & - \\
\hline $\begin{array}{l}\text { Absorb } \\
\text { LMS }\end{array}$ & $\begin{array}{l}\text { Web-Based, } \\
\text { Cloud, SaaS } \\
\text { iPhone / } \\
\text { iPad An- } \\
\text { droid }\end{array}$ & + & + & + & + & + & + & + & + & + & + & + & + \\
\hline
\end{tabular}

Moodle Learning Management System [19] provides educators with a wide range of digital tools to support e-learning.

Schoology [20] is widely used in university education around the world combining dynamic learning management, easy-to-use collaboration interface, and API integra- 
tion. Schoology transforms learning into an interactive environment where groups of stakeholders are formed to improve student achievement.

Talent LMS - cloud-based software - [21] has many attractive features that support synchronous, asynchronous and blended learning. The student portal of the Talent system provides learners with access to useful information and services allowing them to independently search for and interact with educational resources. Built-in development tools allow the creation of interesting educational content; in addition, certification management, SCORM compliance, and gamification features are available. The software is widely used in academia and business.

Canvas Learning Management System [22] is widely used by academic and educational institutions. Canvas has built-in course development tools. Blended learning features combine digital media and innovative classroom teaching methods. There are technological capabilities to support mobile learning, synchronous and asynchronous learning.

Docebo Learning Platform [23] is used in corporate learning; it automates learning management promoting non-formal learning. The system personalizes the experience of the administrator and students through artificial intelligence and provides measurable learning outcomes consistent with the business goals of companies.

iSpringLearn - Cloud-based learning management system [24] - has a simple and modern interface; it takes one day to launch a training course. The platform allows users to download and store training courses, presentations, tests and interactive dialogues created with the use of iSpring products, as well as documents in SCORM 1.2 and 2004 formats (all versions), video (.FLV), audio (.MP3), reference documents (.PDF, .DOC, .XLS), presentations (.PPT), flash files (.SWF). The platform also allows learners to access learning materials on a mobile device without being connected to the Internet, as well as to generate course, user, and event reports.

Brightspace [25] allows users to create inspiring and fun activities. This powerful and flexible learning management platform helps students improve learning outcomes by offering every learner a personalized digital experience.

Absorb Learning Management System [26] is popular in the field of business. The cloud-based learning management system is designed to stimulate learning and improve business performance. User-friendly design and robust features create a fun environment for flexible learning.

\section{$3 \quad$ Results and Discussion}

Education demonstrates high rates of implementation of technological tools that increase the efficiency of educational practices and allow scaling educational content. The developers of the distance learning course "Management of corporate culture of a company in the digital dimension" confirmed the availability of advanced capabilities to generate educational content with the help of modern technological solutions. Learning technology providers are deploying or integrating solutions to dynamically aggregate content from millions of Internet sources creating the most relevant content to meet user requests, including selected topics, keywords, and sites. Intelligent con- 
tent curation allows users to create modern and interesting educational programs containing relevant and necessary data and materials.

In addition, having observed the process of assimilating knowledge and gaining experience, the course curators determined the high effectiveness of educational practices in the digital space, which was significantly influenced by the imitation of the pedagogical style of social learning and the targeted generation of user content by the participants. Q\&A with experts and curators, short videos of typical tasks, blogs / written ideas greatly engage students in the educational process creating a sense of authenticity, affiliation and group partnership. Feedback from curators and peers and stimulation of thematic discussions facilitate the exchange of knowledge, develop creative thinking and form the basis for the generation of innovative solutions. This creates engaging and personalized learning experience that is more likely to be retained, applied, and implemented.

The problem-based approach with the elements of gamification has defined the conceptual integrity of teamwork in the process of the course development and has been applied as a learning model, in which tasks are the starting point for discussion, analysis and solutions, and as a problem-based learning method, which forms the educational stimulus and focuses on educational activities [27]. The problem-based approach was complemented with gamification, which is based on the detection of learning problems and, in particular, can improve the learning process by helping students better absorb and digest the educational material. The strategy of gamification uses game dynamics, mechanics and frameworks for non-game settings [28].

The involvement of the course participants in the solution of urgent problems related to corporate management of medical companies contributed to the development of a sense of affiliation, partnership, and usefulness, as well as stimulated the creative phase of searching for internal intellectual resources to solve the educational tasks set.

Due to the fact that student engagement greatly influences learning outcomes, personalization is the key to effective learning and future career growth. The learning platform addresses the challenge of ensuring personalized learning mainly through a better analysis of student behaviour and the introduction of artificial intelligence algorithms to engage more closely with learners to deliver personalized resources and learning experiences. The platform can collect data on individual learners, screen skill gaps, and propose customized learning programs. As these personalization capabilities develop, the next step is to uniquely adapt learning paths based on student progress [29]. Most course participants confirmed the availability of an individual approach and the selection of educational programs based on the needs of each person; $95 \%$ of the course participants showed a high level of engagement, openness, and activity being online and quickly responding to the requests from curators and peers.

Based on the observations, a universal model of an effective educational process in the digital age has been developed (Fig. 1). 


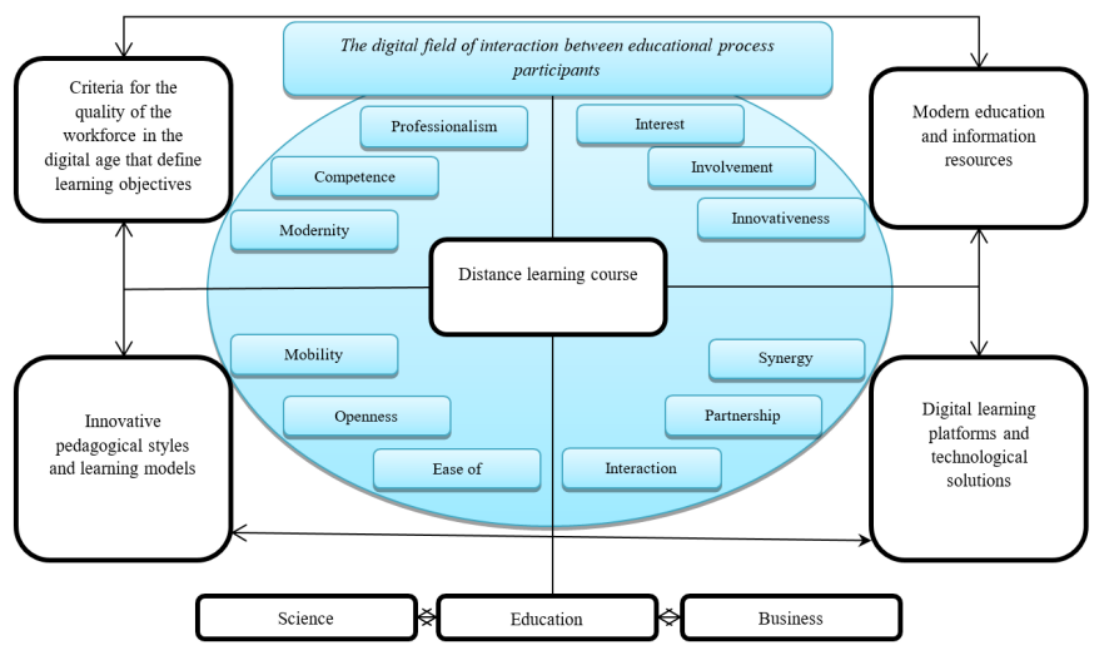

Fig. 1. Model of an effective educational process in the digital age

Note: developed by the authors

\subsection{Prospects for further research}

The proliferation of augmented and virtual reality technology, chat bots and digital personal trainers has stimulated interest in their use in the context of education in order to modernize educational practices. Recently, the efficiency of intelligent agents and social robots in education has been of primary interest [30]. The use of chatbots and digital personal trainers is creating a new style of pedagogy supporting continuous interactive learning and an individual approach to the student. AI-powered tools are becoming personal mentors, providing answers and referrals to the most useful and relevant educational content. Today on the market there is a number of chatbot tools that can be integrated into online learning platforms. Educational technology vendors are aiming to develop "personal trainer" chatbots that will become proactive coaches for every user of the learning platform. Students will be able to request recommended content, track learning progress, ask questions related to the content on their platform, receive notifications about the content that might interest them, or even have a conversation. And as learners interact with the trainer, it will learn from this feedback to evolve and improve coaching [31].

In this regard, further educational experiments will be aimed at exploring the possibilities and directions for the introduction of technological tools based on artificial intelligence, augmented and virtual reality into educational practices.

\section{Conclusion}

Most educational institutions provide scattered education and rely on the 20th century practices that impede the progress and productivity of the modern labour market. 
The main problem that burdens the education system is the dichotomy between teaching humanities and applied sciences. Another problem is the prestige associated with higher education degrees rather than the learning process and the knowledge gained. Therefore, in order to create a quality workforce for the new digital era, private and public organizations must collaborate with educational institutions to transform the academic program in accordance with the challenges of the time. The selection, implementation and adjustment of technological tools in the educational practice of educational institutions promote openness to constant changes, rediscover the most valuable goals of the academic community and continuously improve teaching, learning and the corporate business segment.

The study describes the effectiveness of digital technological solutions in education. Students, postgraduates, teachers, and medical business representatives have tested a comprehensive educational product based on the capabilities of learning management system (LMS) platforms, the implementation of which made it possible to ensure interaction between education, science, and business by facilitating the exchange of knowledge and the generation of innovative solutions. Mobile learning tools allowed us to keep the maximum level of involvement and attention of students reducing distraction and ensuring the strongest online presence. The implementation of advanced e-learning models ensured the effectiveness of the educational process. The focus on the development of the personal potential of each educational process participant made it possible to create a personalized learning environment and evoke a sense of personal significance and importance. The focus on feedback has created a creative communication environment for the exchange of knowledge, thoughts and ideas satisfying participants' educational needs for self-expression and creativity. The collective creativity of the educational process participants made it possible to develop a high-quality corporate culture of the students involved, which became the basis for establishing business partnerships in the system of education, science, and business. Based on the observations, we have developed a universal model of an effective educational process in the digital age.

\section{$5 \quad$ References}

[1] Aparicio, M., Bacao, F. and Oliveira, T. (2016). An e-learning theoretical framework. Journal of Educational Technology Systems, 19(1): 292-307

[2] Valverde-Berrocoso, J., Garrido-Arroyo, M. D. C., Burgos-Videla, C. and MoralesCevallos, M. B. (2020). Trends in Educational Research about e-Learning: A Systematic Literature Review (2009-2018). Sustainability, 12(12): 5153. https://doi.org/10.3390/ $\underline{\mathrm{su} 12125153}$

[3] Rodrigues, H., Almeida, F., Figueiredo, V. and Lopes, S. L. (2019). Tracking e-learning through published papers: A systematic review. Computers \& Education, 136: 87-98. https://doi.org/10.1016/j.compedu.2019.03.007

[4] Sangrà, A., Vlachopoulos, D. and Cabrera, N. (2012). Building an inclusive definition of e-learning: An approach to the conceptual framework. International Review of Research in Open and Distributed Learning, 13(2): 145-159. https://doi.org/10.19173/irrodl.v13i2.1161

[5] Garrison, D. R. (2009). Blended learning as a transformative design approach. In Encyclopedia of Distance Learning, Second Edition (pp. 200-204). IGI Global. https://doi.org/10.4018/978-1-60566-198-8.ch028 
[6] Cachero-Gonzalez, M. L., Medina-Rivilla, A., Dominguez-Garrido, M. C. and MedinaDominguez, M. (2019). The Learning Platform in Distance Higher Education: Students' Perceptions. Turkish Online Journal of Distance Education, 20(1): 71-95. https:// doi.org/10.17718/tojde.522387

[7] González, M. L. C. (2011). Recursos educativos TIC de información, colaboración y aprendizaje. Pixel-Bit. Revista de medios y educación, 39: 69-81.

[8] Bates, A. W. (2015). Teaching in a Digital Age. BC Open Textbooks. Accessed 20 October, 2020 from https://opentextbc.ca/teachinginadigitalage.

[9] Marrhich, A., Lafram, I., Berbiche, N. and El Alami, J. (2020). A Khan Framework-Based Approach to Successful MOOCs Integration in the Academic Context. International Journal of Emerging Technologies in Learning (iJET), 15(12): 4-19. https://doi.org/10.399 1/ijet.v15i12.12929

[10] Liu, Z. Y., Lomovtseva, N. and Korobeynikova, E. (2020). Online learning platforms: Reconstructing modern higher education. International Journal of Emerging Technologies in Learning (iJET), 1513: 4-21. https://doi.org/10.3991/ijet.v15i13.14645

[11] Medina, A. and Dominguez, M.C. (2015). Modelodidáctico-tecnologico para la innovacioneducativa [Didactic-technological model for educational innovation]. In M. L. Cacheiro-González, C. Sánchez \& J. M. González (Eds.), Recursostecnologicos en contextoseducativos [Technological resources in educational contexts]. UNED.

[12] Tanis, C. J. (2020). The seven principles of online learning: Feedback from faculty and alumni on its importance for teaching and learning. Research in Learning Technology, 28. https://doi.org/10.25304/rlt.v28.2319

[13] Elliott, M., Rhoades, N., Jackson, C. M. and Mandernach, B. J. (2015). Professional development: Designing initiatives to meet the needs of online faculty. Journal of Educators Online, 12(1): 160-188. https://doi.org/10.9743/jeo.2015.1.2

[14] Mohammed, P. S. (2019). Towards inclusive education in the age of artificial intelligence: Perspectives, challenges, and opportunities. In Artificial intelligence and inclusive education (pp. 17-37). Springer. https://doi.org/10.1007/978-981-13-8161-4_2

[15] Heffernan, N. T. and Heffernan, C. L. (2014). The ASSISTments ecosystem: Building a platform that brings scientists and teachers together for minimally invasive research on human learning and teaching. International Journal of Artificial Intelligence in Education, 244: 470-497. https://doi.org/10.1007/s40593-014-0024-x

[16] Pienczykowski, D. (2020). What Are The Best LMS For Education And Corporate Training In 2020? Selleo. Accessed 20 October, 2020 from https://selleo.com/blog/best-lmscomparison-in-2020.

[17] Learning Management Systems (LMS). (n.d.). Learning Management Systems (LMS) Overview. Accessed 20 October, 2020 from https://www.trustradius.com/learningmanagement-lms https://doi.org/10.4135/9781412950596.n99

[18] Dron, J. and Anderson, T. (2016). The future of e-learning. In C. A. Haythornthwaite, (Ed.), The Sage Handbook of E-Learning Research (pp. 537-556). SAGE Reference. https://doi.org/10.4135/9781529716696.n26

[19] Moodle Learning Management System. (n.d.). Official website. Accessed 20 October, 2020 from http://www.moodle.com/.

[20] Schoology. (n.d.). Official website. Accessed 20 October, 2020 from https://bit.ly/2Jye zHD.

[21] Talent LMS. (n.d.). Official website. Accessed 20 October, 2020 from http://www.talent.

[22] Canvas Learning Management System. (n.d.). Official website. Accessed 20 October, 2020 from https://canvas.apps.

[23] Docebo Learning Platform. (n.d.). Official website. Accessed 20 October, 2020 from http://www.docebo.com.

[24] iSpringLearn. (n.d.). Official website. Accessed 20 October, 2020 from http://www.ispringsolutions.com. 
[25] Brightspace. (n.d.). Official website. Accessed 20 October, 2020 from https:// www.d21.com.

[26] Absorb Learning Management System. (n.d.). Official website. Accessed 20 October, 2020 from http://www.absorblms.com/.

[27] Panis, I., Setyosari, P., Kuswandi, D. and Yuliati, L. (2020). Design Gamification Models in Higher Education: A Study in Indonesia. International Journal of Emerging Technologies in Learning (iJET), 15(12): 244-255. https://doi.org/10.3991/ijet.v15i12.13965

[28] Stott, A. and Neustaedter, C. (2013). Analysis of gamification in education. Surrey, BC, Canada, 8: 36.

[29] Docebo. (2020). Enterprise E-Learning Trends 2020. A New Era of Learning. Docebo. Accessed 20 October, 2020 from https://uhlberg-advisory.de/wp-content/uploads/2019/ 11/Docebo-Enterprise-E-Learning-Trends-2020.pdf .

[30] Yusuf, B., Walters, L. M. and Sailin, S. N. (2020). Restructuring Educational Institutions for Growth in the Fourth Industrial Revolution (4IR): A Systematic Review. International Journal of Emerging Technologies in Learning (iJET), 15(03): 93-109.

[31] World Economic Forum. (2016). The Future of Jobs - Reports - World Economic Forum. Geneva: World Economic Forum. Accessed 20 October, 2020 from http://www3.weforum.org/docs/WEF_Future_of_Jobs.pdf. https://doi.org/10.3991/ijet.v15 i03.11849

\section{Authors}

Viktor Shurygin - PhD in physics, currently holds the position of the Docent at the Department of Physics in Elabuga Institute (branch) of Kazan (Volga Region) Federal University in Russia. The contact information: Kazan st., 89, Elabuga, Republic of Tatarstan, viktor.shurygin085@gmail.com

Anna Berestova is a PhD in Medical Sciences, currently works as a Docent at the Department of pathological anatomy in I. M. Sechenov First Moscow State Medical University (Sechenov University) in Moscow. The contact information: 8-2, Trubetskaya St., Moscow, berestova_anna89@rambler.ru.

Tatiana Litvinova is a PhD in Pharmaceutical Sciences, currently holds the position of Head of the Department of Pharmacy in I. M. Sechenov First Moscow State Medical University (Sechenov University) in Moscow. The contact information: 8-2, Trubetskaya St., Moscow, litvinova t33@rambler.ru

Eugeny Kolpak currently works in Saint Petersburg State University at the Faculty of Applied Mathematics and Control Process. The contact information: Universitetskaya embarkment, 7/9, Saint Petersburg, ekolpak@ rambler.ru

Alesya Nureyeva now works as an Assistant at the Department of Theory and Methods of Preschool and Primary Education in Elabuga Institute (branch) of Kazan (Volga Region) Federal University in Russia. The contact information: Kazan st., 89, Elabuga, Republic of Tatarstan, anureyeva@rambler.ru

Article submitted 2020-11-06. Resubmitted 2020-12-23. Final acceptance 2021-02-27. Final version published as submitted by the authors. 